\title{
Canadian Recommendations for Use of Methotrexate in Patients with Rheumatoid Arthritis
}

\author{
WANRUCHADA KATCHAMART, JOSIANE BOURRÉ-TESSIER, TIMEA DONKA, JULIE DROUIN, \\ GINA ROHEKAR, VIVIAN P. BYKERK, BOULOS HARAOUI, SHARON LECLERQ, DIANNE P. MOSHER,
} JANET E. POPE, KAM SHOJANIA, JOHN THOMSON, J. CARTER THORNE, CLAIRE BOMBARDIER, and the Canadian 3e Initiative Consensus Group

\begin{abstract}
Objective. To develop recommendations for the use of methotrexate (MTX) in patients with rheumatoid arthritis.

Methods. Canadian rheumatologists who participated in the international $3 \mathrm{e}$ Initiative in Rheumatology (evidence, expertise, exchange) in 2007-2008 formulated 5 unique Canadian questions. A bibliographic team systematically reviewed the relevant literature on these 5 topics. An expert committee consisting of 26 rheumatologists from across Canada was convened, and a set of recommendations was proposed based on the results of systematic reviews combined with expert opinions using a nominal group consensus process.

Results. The 5 questions addressed drug interactions, predictors of response, strategies to reduce non-serious side effects, variables to assess clinical response, and incorporating patient preference into decision-making. The systematic review retrieved 93 pertinent articles; this evidence was presented to the expert committee during the interactive workshop. After extensive discussion and voting, a total of 9 recommendations were formulated: 2 on drug interactions, 1 on predictors of response, 2 on strategies to reduce non-serious side effects, 3 on variables to assess clinical response, and 1 on incorporating patient preferences into decision-making. The level of evidence and the strength of recommendations are reported. Agreement among panelists ranged from $85 \%$ to $100 \%$. Conclusion. Nine recommendations pertaining to the use of MTX in daily practice were developed using an evidence-based approach followed by expert/physician consensus with high level of agreement. (First Release June 1 2010; J Rheumatol 2010;37:1422-30; doi:10.3899/jrheum.090978)
\end{abstract}

\section{Key Indexing Terms: RHEUMATOID ARTHRITIS RECOMMENDATION}

\section{METHOTREXATE EVERYDAY PRACTICE}

\section{GUIDELINE SYSTEMATIC REVIEW}

The need for recommendations. Methotrexate (MTX) is among the most effective and the most commonly prescribed disease modifying antirheumatic drugs (DMARD) in the treatment of rheumatoid arthritis $(\mathrm{RA})^{1-3}$. Despite the advent of new effective biologic agents, MTX is still used as an anchor drug to enhance or maintain the efficacy of
From the Rheumatology Division, Department of Medicine, University of Toronto, Toronto, ON, Canada; Rheumatology Division, Department of Medicine, Siriraj Hospital, Mahidol University, Bangkok, Thailand; Division of Rheumatology, Department of Medicine, Centre Hospitalier de l'Université de Montréal (CHUM), Université de Montréal, Montréal, QC; Rheumatology Division, University of Western Ontario, London, ON; University of Calgary, Calgary, AB; Dalhousie University, Halifax, NS; Rheumatology Division, St. Joseph's Health Care, London, ON; Department of Medicine, University of British Columbia, Vancouver, BC; Department of Medicine, University of Ottawa, Ottawa, ON; The Arthritis Program Research Group, Newmarket, ON; Department of Health Policy, Management, and Evaluation, University of Toronto; and Division of Clinical Decision Making and Health Care, Toronto General Research Institute, University Health Network, Toronto, ON, Canada.

Supported by an unrestricted educational grant from Abbott. Dr. Bombardier holds a Canada Research Chair in Knowledge Transfer for Musculoskeletal Care.

W. Katchamart, MD, FRCP(T), Fellow, Rheumatology Division, Department of Medicine, University of Toronto; Rheumatology Division, Department of Medicine, Siriraj Hospital, Mahidol University; J. Bourré-Tessier, MD, FRCPC, Fellow, Division of Rheumatology, Department of Medicine, CHUM, Université de Montréal; T. Donka, MD, Fellow, Rheumatology Division, Department of Medicine, University of
Toronto; J. Drouin, MD, FRCPC, Fellow, Division of Rheumatology, Department of Medicine, CHUM; G. Rohekar, MD, FRCPC, Assistant Professor, Rheumatology Division, University of Western Ontario; V.P. Bykerk, MD, FRCPC, Assistant Professor, Rheumatology Division, Department of Medicine, University of Toronto; B. Haraoui, MD, FRCPC, Associate Clinical Professor, Division of Rheumatology, Department of Medicine, CHUM; S. LeClerq, MD, FRCPC, Associate Clinical Professor, University of Calgary; D.P. Mosher, MD, FRCPC, Dalhousie University; J.E. Pope, MD, MPH, FRCPC, Professor, Rheumatology Division, St. Joseph's Health Care; K. Shojania, MD, FRCPC, Associate Clinical Professor, Department of Medicine, University of British Columbia; J. Thomson, MD, FRCPC, Lecturer, Department of Medicine, University of Ottawa; J.C. Thorne, MD, FRCPC, Arthritis Program Research Group; C. Bombardier, MD, FRCPC, Rheumatology Division, Department of Medicine, Department of Health Policy, Management, and Evaluation, University of Toronto; Division of Clinical Decision Making and Health Care, Toronto General Research Institute, University Health Network.

Address correspondence to Dr. C. Bombardier, Institute of Work and Health, 481 University Avenue, Toronto, ON, Canada;

E-mail: claire.bombardier@utoronto.ca

Full Release Article. For details see Reprints/Permissions at jrheum.org Accepted for publication December 13, 2009.

See related editorial in this issue 
biologic agents ${ }^{4-10}$. Although MTX has been commonly used in patients with RA over the last 2 decades, clinical practice varies considerably among rheumatologists. It is unclear whether this variation reflects conflicting evidence in the literature or variable application of the evidence in clinical practice.

$3 e$ Initiative in Rheumatology. The 3e Initiative in Rheumatology (evidence, expertise, exchange) is a multinational effort aimed at promoting evidence-based medicine by formulating detailed recommendations addressing clinical problems ${ }^{11}$. The objective of the $3 e$ Initiative 2007-2008 was to develop practical recommendations for the use of MTX in rheumatic disorders, by integrating systematically generated evidence and expert opinion of a broad panel of international rheumatologists. Ten clinical questions on MTX were selected by rheumatologists from 17 countries in Europe and North and South America. The Canadian participants selected 5 additional questions pertaining to drug interaction, monitoring, predictor of response, patient preference, and management of nuisance side effects. The recommendations for the 10 international questions have been published $^{12}$. This article presents the summary of the evidence and the recommendations for the additional Canadian questions.

\section{MATERIALS AND METHODS}

Stakeholders. The Canadian 3e Initiative group consisted of a steering group, a bibliographic team, and an expert committee. The steering group included the principal investigator (CB) and 8 members (VB, BH, SL, DM, JP, KS, JT, and CT). The bibliographic team included 5 rheumatology fellows (WK, JB, JD, TD, and GR) who undertook a systematic review of literature assisted by 3 mentors $(\mathrm{CB}, \mathrm{BH}$, and $\mathrm{JP})$. Twenty-six Canadian rheumatologists from across Canada representing academic and community practices formed the expert committee. They reviewed the evidence from the systematic reviews prepared by the bibliographic team and formulated practice recommendations.

Evidence based approach. The methodology for the systematic review and for the practice recommendations is presented in Figure 1. The 5 Canadian questions (Table 1) were selected by the Canadian Steering Committee at the international meeting held April 27-28, 2007. A systematic search of Medline, Embase, and Cochrane Central Register of Controlled Trials to September 2007 was carried out by the bibliographic team assisted by experienced librarians. The sensitive search strategy included MeSH terms, keywords, and text words related to RA and MTX, and other terms specific to each of the 5 questions (Table 1) included: drug toxicity, adverse effects, drug interaction, patient preference, monitor, treatment outcome, and predictor; there were no restrictions on language. To supplement these electronic bibliographic databases, abstracts from annual scientific meetings were also searched (American College of Rheumatology and European League Against Rheumatism 2005-2007). The reference lists of retrieved articles and reviews were also reviewed. To identify eligible articles, prespecified inclusion and exclusion criteria were applied to the citations obtained from the search strategies. These included population (RA), drug (MTX), and for each question specific interventions and outcome measures. Retained studies were systematically reviewed for quality assessment, data extraction, and synthesis. The evidence was summarized. The level of evidence and grade of recommendation were scored using "The Oxford Centre for Evidence-based Medicine Level of Evidence (May 2001)" (URL: www.cebm.net/index.aspx?o=1047) (Table 2). A series of full systematic reviews ${ }^{13-16}$ underpins the recommendations for the Canadian questions. Four are published in this issue of The Journal ${ }^{14-16}$.

Expert opinion approach. Summaries of the systematic reviews on the 5 topics were presented to the Canadian expert committee at a national meeting in January 2008. Draft recommendations were formulated by the expert committee based on the results of the systematic review. These recommendations were discussed and reworded using the nominal group approach ${ }^{17}$. The final statements were established using a touch-pad voting process with prespecified cutoff agreement. Additionally, participants expressed their level of agreement with the final recommendation using a numeric scale from 0 to 100 .

\section{RESULTS}

For the 5 questions, the literature search identified 9603 citations. After applying the inclusion and exclusion criteria, 93 full-length articles were retained for systematic review. Table 3 presents the final set of 5 recommendations, their level of evidence, the strength of the recommendations, and the agreement among experts based on touch-pad voting.

\section{Recommendation 1: Drug Interactions}

- The majority of drugs including nonsteroidal antiinflammatory drugs (NSAID) may be used safely in combination with $M T X$ in rheumatic diseases (Grade of recommendation $C$ ).

- Trimethoprim and sulfamethoxazole (TMP-SMX) should be avoided in patients treated with MTX (Grade of recommendation C).

These recommendations are based on the systematic review of 21 pharmacokinetics studies, 5 observational studies, and 78 case reports (Level of evidence 4$)^{16}$. Cytopenia and elevation of liver enzymes were the main reported toxicities. Most reports of cytopenia were attributed to the use of concomitant NSAID or high-dose aspirin (ASA) ${ }^{18-31}$. Other medications, e.g., antibiotics, gastroprotective agents, and antihypertensive drugs, have been noted in case reports.

Most NSAID and selective cyclooxygenase-2 inhibitors did not significantly affect the pharmacokinetic profile of MTX $^{32-44}$. For ibuprofen and naproxen, studies showed conflicting results ${ }^{33-35}$. Four studies evaluating high-dose ASA (1.3-4.5 g/day) reported an increase of serum concentration of MTX ${ }^{45-48}$ (Level of evidence 4).

The use of TMP-SMX was mentioned as a risk factor for developing bone marrow suppression in one retrospective case-control study ${ }^{49}$ and in 17 case reports ${ }^{18,50-62}$ (Level of evidence 4).

Cytopenia and elevated liver enzymes were reported with several medications other than NSAID and TMP-SMX, but in only one to a few cases each. Experts agreed that the evidence was not strong enough to make a recommendation. Some experts also proposed that drugs that affect renal function should be used cautiously in patients receiving MTX; however, there was no evidence directly supporting this statement, and the expert committees' agreement for this statement was only $41 \%$. Consequently, it was not included in the final recommendation. Personal non-commercial use only. The Journal of Rheumatology Copyright (C) 2010. All rights reserved. 


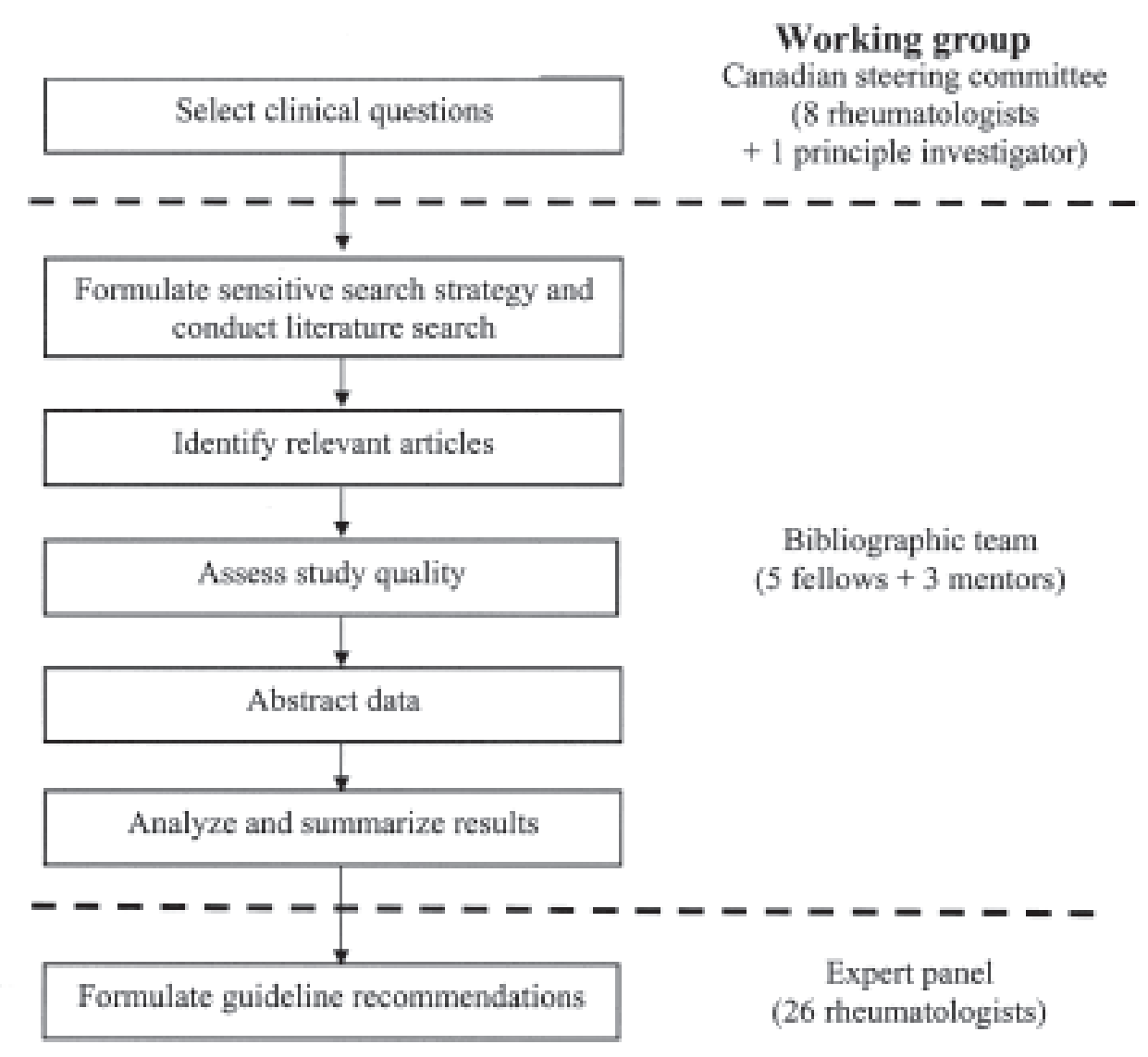

Figure 1. The methodology for the systematic review and the practice recommendations.

Table 1. The 5 Canadian questions formulated for the $3 \mathrm{e}$ Initiative.

1. What drugs (excluding disease modifying antirheumatic drugs and folic/folinic acid) enhance or lower efficacy and/or tolerability/toxicity of methotrexate?

2. What are the predictors of response to methotrexate in rheumatoid arthritis, looking at patients and disease characteristics?

3. What are the management strategies to minimize intolerance of methotrexate, such as nausea, hair loss, mucositis, unwellness, and central nervous system adverse events?

4. Which parameters should be recommended for use in the management of patients with rheumatoid arthritis to assess a clinically meaningful response?

5. Does taking patient preferences into account improve the effectiveness, adherence, and patient satisfaction of methotrexate treatment in patients with rheumatoid arthritis?

\section{Recommendation 2: Prognostic Factors for Response to MTX}

- In determining treatment strategy of patients treated with MTX, characteristics of poor prognosis should be considered, such as female sex and persistent disease activity (Grade of recommendation $B$ ).

This recommendation is based on the systematic review $^{15}$ consisting of 2 metaanalyses ${ }^{63,64}, 3$ cohorts of MTX-treated RA ${ }^{65-67}$, and 4 cohorts using data from randomized controlled trials ${ }^{68-71}$ (Level of evidence $2 b$ ). Both early RA ${ }^{64,65,68-71}$ and long-standing RA ${ }^{66,67}$ were included. The dose of MTX used in these studies ranged from 15 to 25 $\mathrm{mg} / \mathrm{wk}$. Poor clinical response was defined as a lack of evidence of achieving a low disease activity state, measured by Disease Activity Score (DAS) $<2.4^{65,66}$, DAS $28<3.2^{67}$, or Simplified Disease Activity Index score $(\mathrm{SDAI}) \leq 11^{64}$ at the end of followup, while poor radiographic outcome was defined as having evidence of significant radiographic progression, measured by Sharp score ${ }^{70,71}$, Modified Sharp/van der Heijde score ${ }^{69}$, or Modified Larsen score ${ }^{68}$ at the end of followup.

Predictors of poor response to MTX include female sex $^{65-67}$, prior use of DMARD ${ }^{67}$, high disease activity at baseline measured by $\mathrm{DAS}^{65,66}$ or SDAI ${ }^{64}$, and high tender 
Table 2A. Levels of evidence. From the Oxford Centre for Evidence-based Medicine, available from http://www.cebm.net/index.aspx?o=1047; with permission.

\begin{tabular}{|c|c|c|}
\hline Level & Therapy/Prevention, Etiology/Harm & Prognosis \\
\hline $1 \mathrm{a}$ & SR (with homogeneity*) of RCT & $\begin{array}{l}\text { SR (with homogeneity*) of inception cohort } \\
\text { studies; CDR }{ }^{\dagger} \text { validated in different populations }\end{array}$ \\
\hline $1 b$ & $\begin{array}{l}\text { Individual RCT (with narrow confidence } \\
\text { interval }{ }^{\ddagger} \text { ) }\end{array}$ & $\begin{array}{l}\text { Individual inception cohort study with } \geq 80 \% \\
\text { followup; } \mathrm{CDR}^{\dagger} \text { validated in a single population }\end{array}$ \\
\hline $1 \mathrm{c}$ & All or none ${ }^{\S}$ & All or none case series \\
\hline $2 \mathrm{a}$ & SR (with homogeneity*) of cohort studies & $\begin{array}{l}\text { SR (with homogeneity*) of either retrospective } \\
\text { cohort studies or untreated control groups in RCT }\end{array}$ \\
\hline $2 b$ & $\begin{array}{l}\text { Individual cohort study (including low quality } \\
\text { RCT; e.g., }<80 \% \text { followup) }\end{array}$ & $\begin{array}{l}\text { Retrospective cohort study or followup of untreated } \\
\text { control patients in an RCT; derivation of } \mathrm{CDR}^{\dagger} \text { or } \\
\text { validated on split-sample } \\
\S \S \text { only }\end{array}$ \\
\hline $2 \mathrm{c}$ & "Outcomes" research; ecological studies & "Outcomes" research \\
\hline $3 \mathrm{a}$ & SR (with homogeneity*) of case-control studies & \\
\hline $3 b$ & Individual case-control study & \\
\hline 4 & $\begin{array}{l}\text { Case series (and poor quality cohort and } \\
\text { case-control studies } \$ \S)\end{array}$ & $\begin{array}{l}\text { Case-series (and poor quality prognostic cohort } \\
\text { studies**) }\end{array}$ \\
\hline 5 & $\begin{array}{l}\text { Expert opinion without explicit critical } \\
\text { appraisal, or based on physiology, bench } \\
\text { research, or "first principles" }\end{array}$ & $\begin{array}{l}\text { Expert opinion without explicit critical appraisal, or } \\
\text { based on physiology, bench research, or "first } \\
\text { principles" }\end{array}$ \\
\hline
\end{tabular}

Table $2 B$. Grades of recommendation.

$\begin{array}{ll}\text { A } & \text { Consistent level } 1 \text { studies } \\ \text { B } & \text { Consistent level } 2 \text { or } 3 \text { studies or extrapolations from level } 1 \text { studies } \\ \text { C } & \text { Level } 4 \text { studies or extrapolations from level } 2 \text { or } 3 \text { studies } \\ \text { D } & \text { Level } 5 \text { evidence or troublingly inconsistent or inconclusive studies of any level }\end{array}$

Users can add a minus sign "--" to denote the level if that fails to provide a conclusive answer because of: EITHER a single result with a wide confidence interval (such that, for example, an ARR in an RCT is not statistically significant but whose confidence intervals fail to exclude clinically important benefit or harm); OR a SR with troublesome (and statistically significant) heterogeneity. Such evidence is inconclusive, and therefore can generate only Grade D recommendations. * Homogeneity: A SR free of worrisome variations (heterogeneity) in the directions and degrees of results between individual studies. Not all SR with statistically significant heterogeneity need be worrisome, and not all worrisome heterogeneity need be statistically significant. As noted above, studies displaying worrisome heterogeneity should be tagged with a "-" at the end of their designated level. ${ }^{\dagger}$ Clinical decision rule. (Algorithms or scoring systems that lead to a prognostic estimation or a diagnostic category). ${ }^{\ddagger}$ See note no. 2 for advice on how to understand, rate, and use trials or other studies with wide confidence intervals. ${ }^{\S}$ Met when all patients died before the prescription became available, but some now survive on it; or when some patients died before the prescription became available, but none now die on it. $\$ \S$ Poor quality cohort study: one that failed to clearly define comparison groups and/or failed to measure exposures and outcomes in the same (preferably blinded) objective way in both exposed and non-exposed individuals and/or failed to identify or appropriately control known confounders and/or failed to carry out a sufficiently long and complete followup of patients. By poor quality case-control study we mean one that failed to clearly define comparison groups and/or failed to measure exposures and outcomes in the same (preferably blinded) objective way in both cases and controls and/or failed to identify or appropriately control known confounders. ${ }^{\S \S}$ Split-sample validation is achieved by collecting all the information in a single tranche, then artificially dividing this into "derivation" and "validation" samples. ** Poor quality prognostic cohort study: one in which sampling was biased in favor of patients who already had the target outcome, or the measurement of outcomes was accomplished in $<80 \%$ of study patients, or outcomes were determined in an unblinded, nonobjective way, or there was no correction for confounding factors.

"Extrapolations": where data are used in a situation that has potentially clinically more important differences than the original study situation.

SR: systemic review; RCT: randomized controlled trial; CDR: clinical decision rule.

joint count ${ }^{67}$. Other predictors considered in the published literature were not found to be independent predictors of clinical response in both early and established RA.

Predictors of poor radiographic outcome include high baseline erythrocyte sedimentation rate $(\mathrm{ESR})^{68,69}$, particu- larly in patients with persistent evidence of inflammation, e.g., high DAS28 ${ }^{69}$, ESR $^{69,71}$, and C-reactive protein $(\mathrm{CRP})^{69,71}$.

These studies consistently identify disease activity as a predictor of poor response to MTX. Since different meas- 
Table 3. Canadian recommendations on the use of methotrexate (MTX) in patients with rheumatoid arthritis (RA), level of evidence, strength of recommendations, and voting agreement.

\begin{tabular}{|c|c|c|c|}
\hline Recommendation & $\begin{array}{l}\text { Level of } \\
\text { Evidence }\end{array}$ & $\begin{array}{c}\text { Grade of } \\
\text { Recommendation }\end{array}$ & $\begin{array}{l}\text { Percentage } \\
\text { Agreement }\end{array}$ \\
\hline \multicolumn{4}{|l|}{ 1. Drug interaction } \\
\hline Trimethoprim-sulfamethoxazole should be avoided in patients treated with MTX & 4 & $\mathrm{C}$ & 97 \\
\hline \multicolumn{4}{|l|}{ 2. Prognostic factor of clinical and radiographic responses } \\
\hline \multicolumn{4}{|l|}{ 3. Management of non-serious side effects } \\
\hline $\begin{array}{l}\text { To minimize non-serious gastrointestinal effects of MTX, one switch from oral to parenteral } \\
\text { (subcutaneous or intramuscular) MTX }\end{array}$ & al 4 & $\mathrm{D}$ & 97 \\
\hline Other strategies to minimize non-serious side effects include splitting the dose of MTX & 4 & $\mathrm{D}$ & 87 \\
\hline \multicolumn{4}{|l|}{ 4. Parameter used in the assessment of clinical response } \\
\hline Use of validated outcome measures to reach a target of low disease activity or remission & 1a & A & 97 \\
\hline $\begin{array}{l}\text { Patients need to be educated on their disease and treatment options and involved in the } \\
\text { decision-making process }\end{array}$ & $2 b$ & $\mathrm{D}$ & 97 \\
\hline
\end{tabular}

NSAID: nonsteroidal antiinflammatory drug.

ures of disease activity were used across the studies, the expert panel decided to use the general term "persistent disease activity" instead of specifying the individual parameters of disease activity (e.g., DAS28, tender joint count, etc.).

\section{Recommendation 3: Management of Non-serious Side Effects}

1. To minimize non-serious gastrointestinal side effects of MTX one could try to switch from oral to parenteral (subcutaneous or intramuscular) MTX (Grade of recommendation $D)$.

2. Other strategies to minimize non-serious side effects could include splitting of the dose of MTX (Grade of recommendation D).

The systematic review "Strategies to Reduce "Nuisance" Side-Effects of Methotrexate"13 failed to find direct evidence to support the benefit of modalities to reduce nuisance side effects. Experimental evidence from appropriately designed clinical trials was not available; these recommendations are, therefore, based on extrapolation from studies demonstrating that intramuscular (im) form is more tolerable than oral form in 2 cohorts (Level of evidence 4). In a survey of patients forced to switch to oral MTX when the supply of im MTX ran out ${ }^{72}, 69(48 \%)$ patients who tolerated im MTX could not tolerate taking it orally due to nausea $(\mathrm{p}<0.001)$. In a RA cohort of 212 patients $^{73}$, switching from oral to im MTX was found to decrease gastrointestinal side effects: after 6 months only 9\% terminated im MTX due to adverse events.
The recommendation for splitting the dose of MTX was based entirely on expert opinion due to a lack of evidence addressing this issue. The only evidence related to the dose of MTX was from an open-labeled $\mathrm{RCT}^{74}$ showing that starting MTX treatment at a dose of $25 \mathrm{mg}$ /week was associated with a higher rate of minor toxicity (gastrointestinal except liver toxicity) as compared to $15 \mathrm{mg} /$ week (28\% vs $17 \%, \mathrm{p}<0.05$, for $25 \mathrm{vs} 15 \mathrm{mg} / \mathrm{wk}$, respectively) (Level of evidence 4).

Other strategies or modalities have been studied; however, the expert panel chose not to make recommendations on these modalities due to insufficient evidence ${ }^{75-77}$.

\section{Recommendation 4: Parameter Used in the Assessment of Clinical Response}

1. Use of validated outcome measures to reach a target of low disease activity or remission is recommended (Grade of recommendation $A$ ).

2. Joint counts should be included in the assessment of disease activity in RA (Grade of recommendation B).

3. In addition to joint counts, other parameters in the assessment of disease activity in RA could include validated measures of global assessments and acute-phase reactants (Grade of recommendation B).

The systematic review on this topic showed that there was no evidence for which parameters should be used in management of patients with RA to assess a clinically meaningful response in daily practice ${ }^{14}$. These recommendations were extrapolated from 3 randomized controlled trials of tight control strategy in RA identified by experts (Level of Personal non-commercial use only. The Journal of Rheumatology Copyright @ 2010 . All rights reserved. 
evidence 1a). These studies ${ }^{78-80}$ demonstrated that targeted care aiming at remission or low disease activity and frequent followup (every month) may lead to more aggressive treatment, resulting in better disease states/clinical outcomes than usual care in RA. These studies used different outcome measures to assess the clinical response. DAS and DAS28 were used in the TICORA study ${ }^{78}$ and in Fransen, et $a l^{79}$, respectively; whereas in the CAMERA study ${ }^{80}$, a computer program was used to calculate the $50 \%$ improvement response in swollen joint count and the improvement of at least 2 out of 3 of the following variables: number of tender joints, ESR, and patient global assessment of general well-being.

Based on the results of these $3 \mathrm{RCT}$, all experts but one agreed that in clinical practice validated outcome measures aiming at remission or at least low disease activity should be used to assess clinically meaningful response. Although there is a lack of evidence on which parameter should be used in daily practice, the group reached the following consensus: the use of patient or physician global assessments alone is not sufficient; joint assessment is the most important parameter reflecting disease activity; and other variables including patient global assessment, physician global assessment, and inflammatory marker, e.g., ESR or CRP, should be considered in addition to joint count in the assessment of RA disease activity.

\section{Recommendation 5: Patient preference}

- Patients need to be educated on their disease and treatment options and involved in the decision-making process (Grade of recommendation D).

This recommendation is entirely expert-based. There is no evidence in the literature that incorporating RA patients' preference in the therapeutic decision improves treatment outcomes, adherence to medications, or patient satisfaction in those taking MTX. Nonetheless, the expert panels agreed that shared decision-making should incorporate patient's preference, research evidence, and knowledge of the patient's clinical state. In addition, the expert panel was also aware of the role and impact of patient education on the treatment outcomes based on a Cochrane review, "Patient education for adults with RA"81 (Level of evidence $2 b$ ). The results of this review supported a beneficial effect of patient education programs in terms of pain (small benefit, $4 \%$ or $0.2 \mathrm{~cm}$ in the visual analog scale), functional impairment (moderate benefit, $10 \%$ or 0.16 points on the Health Assessment Questionnaire score), tender joint count (moderate benefit, $9 \%$ or 1.3 points on the Ritchie index), patient's overall assessment [moderate benefit, $12 \%$ or 0.28 points on the Arthritis Impact Measurement Scales 2 (AIMS2) arthritis subscale], and psychological status (moderate benefit, $5 \%$ or 0.15 points on the AIMS2 affect subscale and $12 \%$ or 0.14 points on the Hospital Anxiety and Depression Scale). However, no lasting benefits were found at one year after the end of the educational program. These effects were related chiefly to educational programs, as opposed to simple patient information.

\section{DISCUSSION}

These recommendations were developed using an evidence-based approach. A methodology team conducted systematic reviews using a comprehensive search in 2 bibliographic databases, Medline and Embase, plus screening of abstracts of scientific meetings. A group of clinical experts considered the quality of the evidence from these systematic reviews as well as the clinical relevance, applicability, and values and preferences of patients and practitioners to ensure that recommendations meet their needs.

We followed an established group decision method, the nominal group process. This included a representative expert panel of academic and community rheumatologists from across Canada, who openly discussed the evidence from the literature followed by a silent voting process. We used the touch-pad methodology with prespecified cutoff levels of agreement to generate the final recommendations. Several rounds of rewording and revoting were sometimes required to reach the agreed cutoff. This process ensured that the final recommendations were evidence-driven as well as clinically relevant.

Of the 15 questions initially proposed by the Canadian steering committee at the international meeting of the $3 \mathrm{e}$ Initiative, 10 were also rated highly by the 17 participating countries. Recommendations for these 10 top-rated international questions have been published ${ }^{12}$. This article addressed the 5 remaining Canadian questions. Although these 5 questions are clinically important, the 10 international questions addressing MTX initiation, monitoring, and safety were considered of higher priority by the international experts. In their selection of the top 10 questions, experts may also have taken into account whether there would be sufficient evidence in the literature to generate robust recommendations. Indeed, we found that many of the 5 questions lacked high-quality studies, or studies were not specifically related to MTX treatment; for instance, no study directly addressed which of the objective parameters should be used to assess the clinical response to MTX, or should patient preference be taken into account in MTX treatment decisions. Our recommendations were, therefore, based on expert opinion, resulting in the lowest "grade of recommendation" on the Oxford scale. Nevertheless, our recommendations emphasize the need for future research in these clinically important areas.

Of several recent guidelines available to assist in the management of patients with $\mathrm{RA}^{82-86}$, none addressed our question on drug interactions. Most guidelines addressed none or just a few of our 5 questions, but where our questions were addressed, the result was generally congruent with our recommendations. 
In conclusion, using a nominal group process and scientific evidence, we provide recommendations for the use of MTX in patients with RA to assist specialists in everyday practice. These 9 Canadian recommendations complement the 10 recommendations from the international $3 e$ Initiative expert panel. These recommendations are intended to benefit all patients with RA who receive MTX therapy.

\section{ACKNOWLEDGMENT}

Canadian $3 e$ Initiative Consensus Group: Kenneth Blocka, Cathy Elizabeth Flanagan, Paul Davis, Wojciech Olszynski, Vandana Ahluwalia, Michel Zummer, Gilles Boire, Jamie Henderson, Barry Koehler, Philip Baer, Zareen Ahmad, Anne St-Pierre, Martin Cohen, Maysan Abu-Hakima, Majed Khraishi, Elaine Soucy, and Jacob Karsh.

\section{REFERENCES}

1. Tugwell P, Bennett K, Gent M. Methotrexate in rheumatoid arthritis. Indications, contraindications, efficacy, and safety. Ann Intern Med 1987;107:358-66.

2. Felson DT, Anderson JJ, Meenan RF. The comparative efficacy and toxicity of second-line drugs in rheumatoid arthritis: results of two metaanalyses. Arthritis Rheum 1990;33:1449-61.

3. Felson DT, Anderson JJ, Meenan RF. Use of short-term efficacy/toxicity tradeoffs to select second-line drugs in rheumatoid arthritis. A metaanalysis of published clinical trials. Arthritis Rheum 1992;35:1117-25.

4. van der Heijde D, Burmester G, Melo-Gomes J, Codreanu C, Mola EM, Pedersen R, et al. The safety and efficacy of adding etanercept to methotrexate or methotrexate to etanercept in moderately active rheumatoid arthritis patients previously treated with monotherapy. Ann Rheum Dis 2008;67:182-8.

5. Lipsky PE, van der Heijde D, St. Clair EW, Furst DE, Breedveld FC, Kalden JR, et al. Infliximab and methotrexate in the treatment of rheumatoid arthritis. N Engl J Med 2000;343:1594-602.

6. St. Clair W, van der Heijde D, Smolen J, Maini R, Bathon J, Emery $\mathrm{P}$, et al. Combination of infliximab and methotrexate therapy for early rheumatoid arthritis: A randomized, controlled trial. Arthritis Rheum 2004;50:3432-43.

7. Breedveld FC, Weisman MH, Kavanaugh AF, Cohen SB, Pavelka $\mathrm{K}$, van Vollenhoven R, et al. The PREMIER study: A multicenter, randomized, double-blind clinical trial of combination therapy with adalimumab plus methotrexate versus methotrexate alone or adalimumab alone in patients with early, aggressive rheumatoid arthritis who had not had previous methotrexate treatment. Arthritis Rheum 2006;54:26-37.

8. Heiberg MS, Rodevand E, Mikkelsen K, Kaufmann C, Didriksen A, Mowinckel $\mathrm{P}$, et al. Adalimumab and methotrexate is more effective than adalimumab alone in patients with established rheumatoid arthritis: results from a 6-month longitudinal, observational, multicentre study. Ann Rheum Dis 2006;65:1379-83.

9. Cohen SB, Emery P, Greenwald MW, Dougados M, Furie RA, Genovese MC, et al. Rituximab for rheumatoid arthritis refractory to anti-tumor necrosis factor therapy: Results of a multicenter, randomized, double-blind, placebo-controlled, phase III trial evaluating primary efficacy and safety at twenty-four weeks. Arthritis Rheum 2006;54:2793-806.

10. Emery P, Fleischmann R, Filipowicz-Sosnowska A, Schechtman J, Szczepanski L, Kavanaugh A, et al. The efficacy and safety of rituximab in patients with active rheumatoid arthritis despite methotrexate treatment: Results of a phase IIB randomized, double-blind, placebo-controlled, dose-ranging trial. Arthritis Rheum 2006;54:1390-400.

11. Sidiropoulos PI, Hatemi G, Song IH, Avouac J, Collantes E,
Hamuryudan V, et al. Evidence-based recommendations for the management of ankylosing spondylitis: systematic literature search of the 3E Initiative in Rheumatology involving a broad panel of experts and practising rheumatologists. Rheumatology 2008;47:355-61.

12. Visser K, Katchamart W, Loza E, Martinez-Lopez JA, Salliot C, Trudeau J, et al. Multinational evidence-based recommendations for the use of methotrexate in rheumatic disorders with a focus on rheumatoid arthritis: integrating systematic literature research and expert opinion of a broad international panel of rheumatologists in the 3e Initiative. Ann Rheum Dis 2009;68:1086-93.

13. Rohekar G, Pope J. Strategies to reduce "nuisance" side-effects of methotrexate: A systematic review. (Manuscript in preparation)

14. Katchamart W, Bombardier C. Systematic monitoring of disease activity using an outcome measure improves outcomes in rheumatoid arthritis. J Rheumatol 2010 May 1. Epub ahead of print

15. Drouin J, Haraoui B. Predictors of clinical response and radiographic progression in rheumatoid patients treated with methotrexate monotherapy. J Rheumatol 2010;37:1405-10.

16. Bourre-Tessier J, Haraoui B. Methotrexate drug interactions in the treatment of rheumatoid arthritis: a systematic review. J Rheumatol 2010;37:1416-21

17. Fink A, Kosecoff J, Chassin M, Brook RH. Consensus methods: characteristics and guidelines for use. Am J Public Health 1984;74:979-83.

18. Franck H, Rau R, Herborn G. Thrombocytopenia in patients with rheumatoid arthritis on long-term treatment with low dose methotrexate. Clin Rheumatol 1996;15:266-70.

19. Singh RR, Malaviya AN, Pandey JN, Guleria JS. Fatal interaction between methotrexate and naproxen [letter]. Lancet 1986;i:1390.

20. Kraus A, Alarcon-Segovia D. Low dose MTX and NSAID induced "mild" renal insufficiency and severe neutropenia [letter] J Rheumatol 1991;18:1274.

21. Ohosone Y, Okano Y, Kameda H, Hama N, Mimori T, Akizuki M, et al. Clinical characteristics related to methotrexate-induced pancytopenia [letter]. Clin Rheumatol 1997;16:321-3.

22. Calvo-Romero JM. Severe pancytopenia associated with low-dose methotrexate therapy for rheumatoid arthritis. Ann Pharmacother 2001;35:1575-7.

23. Basin KS, Escalante A, Beardmore TD. Severe pancytopenia in a patient taking low dose methotrexate and probenecid. J Rheumatol 1991;18:609-10.

24. Frenia ML, Long KS. Methotrexate and nonsteroidal antiinflammatory drug interactions. Ann Pharmacother 1992;26:234-7.

25. Thonofer R, Kriessmayr M, Thonofer U, Wipfler E, Uitz E, Bahadori B, et al. Rheumatoid arthritis patients with therapy-induced myelodysplastic syndrome present with long-term remission after recovery. Scand J Rheumatol 2007;36:149-50.

26. Berthelot JM, Maugars Y, Hamidou M, Chiffoleau A, Barrier J, Grolleau JY, et al. Pancytopenia and severe cytopenia induced by low-dose methotrexate. Eight case-reports and a review of one hundred cases from the literature (with twenty-four deaths). Rev Rhum (Engl Ed) 1995;62:477-86.

27. Tanaka Y, Shiozawa K, Nishibayashi Y, Imura S. Methotrexate induced early onset pancytopenia in rheumatoid arthritis: Drug allergy? Idiosyncrasy? [letter]. J Rheumatol 1992;19:1320-1.

28. Laroche F, Perrot S, Menkes CJ. Pancytopenia in rheumatoid arthritis patients receiving methotrexate [French]. Presse Med 1996;25:1144-6.

29. Serraj K, Federici L, Maloisel F, Alt M, Andres E. Pancytopenia related to low-dose methotrexate: study of five cases and review of the literature. Rev Med Interne 2007;28:584-8.

30. Maier WP, Leon-Perez R, Miller SB. Pneumonitis during low-dose methotrexate therapy. Arch Intern Med 1986;146:602-3. 
31. Doolittle GC, Simpson KM, Lindsley HB. Methotrexate-associated, early-onset pancytopenia in rheumatoid arthritis. Arch Intern Med 1989;149:1430-1.

32. Karim A, Tolbert DS, Hunt TL, Hubbard RC, Harper KM, Geis GS. Celecoxib, a specific cox-2 inhibitor, has no significant effect on methotrexate pharmacokinetics in patients with rheumatoid arthritis. J Rheumatol 1999;26:2539-43.

33. Tracy TS, Worster T, Bradley JD, Greene PK, Brater DC. Methotrexate disposition following concomitant administration of ketoprofen, piroxicam and flurbiprofen in patients with rheumatoid arthritis. Br J Clin Pharmacol 1994;37:453-6.

34. Stewart CF, Fleming RA, Arkin CR, Evans WE. Coadministration of naproxen and low-dose methotrexate in patients with rheumatoid arthritis. Clin Pharmacol Ther 1990;47:540-6.

35. Skeith KJ, Russell AS, Jamali F, Coates J, Friedman H. Lack of significant interaction between low dose methotrexate and ibuprofen or flurbiprofen in patients with arthritis. J Rheumatol 1990;17:1008-10.

36. Vakily M, Amer F, Kukulka MJ, Andhivarothai N. Coadministration of lansoprazole and naproxen does not affect the pharmacokinetic profile of methotrexate in adult patients with rheumatoid arthritis. J Clin Pharmacol 2005;45:1179-86.

37. Hartmann SN, Rordorf CM, Milosavljev S, Branson JM, Chales GH, Juvin RR, et al. Lumiracoxib does not affect methotrexate pharmacokinetics in rheumatoid arthritis patients. Ann Pharmacother 2004;38:1582-7.

38. Hamilton SF, Campbell NR, Kara M, Watson J, Connors M. The effect of ingestion of ferrous sulfate on the absorption of oral methotrexate in patients with rheumatoid arthritis. J Rheumatol 2003;30:1948-50.

39. Schwartz JI, Agrawal NG, Wong PH, Bachmann KA, Porras AG, Miller JL, et al. Lack of pharmacokinetic interaction between rofecoxib and methotrexate in rheumatoid arthritis patients. J Clin Pharmacol 2001;41:1120-30.

40. Iqbal MP, Baig JA, Ali AA, Niazi SK, Mehboobali N, Hussain MA. The effects of non-steroidal anti-inflammatory drugs on the disposition of methotrexate in patients with rheumatoid arthritis. Biopharm Drug Dispos 1998;19:163-7.

41. Hubner G, Sander O, Degner FL, Türck D, Rau R. Lack of pharmacokinetic interaction of meloxicam with methotrexate in patients with rheumatoid arthritis. J Rheumatol 1997;24:845-51.

42. Gumbhir-Shah K, Cevallos WH, DeCleene SA, Korth-Bradley JM. Lack of interaction between bromfenac and methotrexate in patients with rheumatoid arthritis J Rheumatol 1996;23:984-9.

43. Ahern M, Booth J, Loxton A, McCarthy P, Meffin P, Kevat S. Methotrexate kinetics in rheumatoid arthritis: Is there an interaction with nonsteroidal antiinflammatory drugs? J Rheumatol 1988;15:1356-60.

44. Svendsen KB, Bech JN, Pfeiffer-Jensen M, Stengaard-Pederson K, Pederson EB. Urinary excretion of alpha-GST and albumin in rheumatoid arthritis patients treated with methotrexate or other DMARDs alone or in combination with NSAIDs. Scand J Rheumatol 2005;34:34-9.

45. Stewart CF, Fleming RA, Germain BF, Seleznick MJ, Evans WE. Aspirin alters methotrexate disposition in rheumatoid arthritis patients. Arthritis Rheum 1991;34:1514-20.

46. Seideman P, Muller-Suur R. Renal effects of aspirin and low dose methotrexate in rheumatoid arthritis. Ann Rheum Dis 1993;52:613-5.

47. Tracy TS, Krohn K, Jones DR, Bradley JD, Hall SD, Brater DC. The effects of a salicylate, ibuprofen, and naproxen on the disposition of methotrexate in patients with rheumatoid arthritis. Eur J Clin Pharmacol 1992;42:121-5.

48. Furst DE, Herman RA, Koehnke R, Ericksen N, Hash L, Riggs CE, et al. Effect of aspirin and sulindac on methotrexate clearance.
J Pharm Sci 1990;79:782-6.

49. Al-Awadhi A, Dale P, McKendry R. Pancytopenia associated with low dose methotrexate therapy. A regional survey. J Rheumatol 1993;20:1121-5.

50. Kaneko Y, Suwa A, Ikeda Y, Hirakata M. Pneumocystis jiroveci pneumonia associated with low-dose methotrexate treatment for rheumatoid arthritis: report of two cases and review of the literature. Mod Rheumatol 2006;16:36-8.

51. Sosin M, Handa S. Low dose methotrexate and bone marrow suppression. BMJ 2003;326:266-7.

52. Saravana S, Lalukotta K. Myelotoxicity due to methotrexate - an iatrogenic cause [letter]. Eur J Haematol 2003;71:315-6.

53. Chevrel G, Brantus JF, Sainte-Laudy J, Miossec P. Allergic pancytopenia to trimethoprim-sulphamethoxazole for pneumocystis carinii pneumonia following methotrexate treatment for rheumatoid arthritis [letter]. Rheumatology 1999;38:475-6.

54. Steuer A, Gumpel JM. Methotrexate and trimethoprim: a fatal interaction [letter]. Br J Rheumatol 1998;37:105-6.

55. Nygaard H. Pancytopenia secondary to methotrexate therapy in rheumatoid arthritis: comment on the article by Gutierrez-Urena, et al [letter]. Arthritis Rheum 1997;40:194-5.

56. Govert J, Patton S, Fine R. Pancytopenia from using trimethoprim and methotrexate [letter]. Ann Intern Med 1992;117:877-8.

57. Groenendal H, Rampen FH. Methotrexate and trimethoprim-sulphamethoxazole - a potentially hazardous combination. Clin Exp Dermatol 1990;15:358-60.

58. Jeurissen M, Boerbooms A, van de Putte L. Pancytopenia and methotrexate with trimethoprim-sulfamethoxazole [letter]. Ann Intern Med 1989;111:261.

59. Buchbinder R, Hall S, Ryan PFJ, Littlejohn GO, Harkness AJL. Severe bone marrow failure due to low dose oral methotrexate [letter]. J Rheumatol 1988;15:1586-8.

60. Thevenet JP, Ristori JM, Cure H, Mizony MH, Bussiere JL. Pancytopenia during treatment of rheumatoid arthritis with methotrexate after administration of trimethoprim-sulfamethoxazole [French]. Presse Med 1987;16:1487.

61. Thomas MH, Gutterman LA. Methotrexate toxicity in a patient receiving trimethoprim-sulfamethoxazole. J Rheumatol 1986;13:440-1.

62. Maricic M, Davis M, Gall E. Megaloblastic pancytopenia in a patient receiving concurrent methotrexate and trimethoprim-sulfamethoxazole treatment. Arthritis Rheum 1986;29:133-5.

63. The effect of age and renal function on the efficacy and toxicity of methotrexate in rheumatoid arthritis. Rheumatoid Arthritis Clinical Trial Archive Group. J Rheumatol 1995;22:218-23.

64. Aletaha D, Funovits J, Keystone E, Smolen J. Disease activity early in the course of treatment predicts response to therapy after one year in rheumatoid arthritis patients. Arthritis Rheum 2007; $56: 3226-35$

65. Wessels J, van der Kooij SM, le Cessie S, Kievit W, Barerra P, Allaart CF, et al. A clinical pharmacogenetic model to predict the efficacy of methotrexate monotherapy in recent-onset rheumatoid arthritis. Arthritis Rheum 2007;56:1765-75.

66. Hoekstra M, van Ede AE, Haagsma CJ, van de Laar MAFJ, Huizinga TWJ, Kruijsen MWM, et al. Factors associated with toxicity, final dose, and efficacy of methotrexate in patients with rheumatoid arthritis. Ann Rheum Dis 2003;62:423-6.

67. Lie E, Heiberg MS, Nordvag BY, Rodevand E, Kaufmann C, Mikkelsen K, et al. Predictors of response to methotrexate treatment: Results from a longitudinal observational study of 876 patients with RA. Ann Rheum Dis 2006;65 Suppl II:342.

68. Rau R, Herborn G, Menninger H, Sangha O. Progression in early erosive rheumatoid arthritis: 12 month results from a randomized controlled trial comparing methotrexate and gold sodium 
thiomalate. Br J Rheumatol 1998;37:1220-6.

69. Smolen JS, van der Heijde D, St. Clair W, Emery P, Bathon JM, Keystone E, et al. Predictors of joint damage in patients with early rheumatoid arthritis treated with high-dose methotrexate with or without concomitant infliximab: Results from the ASPIRE trial. Arthritis Rheum 2006;54:702-10.

70. Van der Heijde D, Landewe R, Sharp JT, Bathon J, Patra K, Spencer-Green G. Baseline CRP concentrations predict radiographic progression in MTX-naive patients with early RA: Subanalysis of the PREMIER study. Ann Rheum Dis 2005;64 Suppl III:436.

71. Weinblatt M, Keystone EC, Cohen MD, Freundlich B, Li J, Chon $\mathrm{Y}$, et al. Predictors of poor radiographic response in rheumatoid arthritis subjects treated with methotrexate: preliminary analysis from ERA and TEMPO studies [abstract]. Arthritis Rheum 2006;54 Suppl:S181.

72. Wegrzyn J, Adeleine P, Miossec P. Better efficacy of methotrexate given by intramuscular injection than orally in patients with rheumatoid arthritis. Ann Rheum Dis 2004;63:1232-4.

73. Linde L, Hetland ML, Ostergaard M. Drug survival and reasons for discontinuation of intramuscular methotrexate: a study of 212 consecutive patients switching from oral methotrexate. Scand J Rheumatol 2006;35:102-6.

74. Schnabel A, Reinhold-Keller E, Willmann V, Gross W. Tolerability of methotrexate starting with 15 or $25 \mathrm{mg} /$ week for rheumatoid arthritis. Rheumatol Int 1994;14:33-8.

75. Luis M, Pacheco-Tena C, Cazarín-Barrientos J, Lino-Pérez L, Goycochea MV, Vázquez-Mellado J, et al. Comparison of two schedules for administering oral low-dose methotrexate (weekly versus every-other-week) in patients with rheumatoid arthritis in remission: A twenty-four-week, single-blind, randomized study. Arthritis Rheum 1999;42:2160-5.

76. Wu Y, Lao Z, Zhang Z. Clinical observation on small doses Tripterygium wilfordii polyglycoside combined with methotrexate in treating rheumatoid arthritis. Zhongguo Zhong Xi Yi Jie He Za Zhi 2001;21:895-6.

77. Yoshida T, Hirakata M. Therapeutic benefits of irsogladine maleate on aphthous stomatitis induced by methotrexate in rheumatoid arthritis. J Rheumatol 2003;30:2082-3.
78. Grigor C, Capell H, Stirling A, McMahon AD, Lock P, Vallance R, et al. Effect of a treatment strategy of tight control for rheumatoid arthritis (the TICORA study): a single-blind randomised controlled trial. Lancet 2004;364:263-9.

79. Fransen J, Moens H, Speyer I, van Riel P. Effectiveness of systematic monitoring of rheumatoid arthritis disease activity in daily practice: a multicentre, cluster randomised controlled trial. Ann Rheum Dis 2005;64:1294-8.

80. Verstappen SMM, Jacobs JWG, van der Veen MJ, Heurkens AHM, Schenk Y, ter Borg EJ, et al. Intensive treatment with methotrexate in early rheumatoid arthritis: aiming for remission. Computer Assisted Management in Early Rheumatoid Arthritis (CAMERA, an open-label strategy trial). Ann Rheum Dis 2007;66:1443-9.

81. Riemsma R, Kirwan JR, Taal E, Rasker JJ. Patient education for adults with rheumatoid arthritis. Cochrane Database Syst Rev 2003: CD003688

82. Saag KG, Gim GT, Patkar NM, Anuntiyo J, Finney C, Curtis JR, et al. American College of Rheumatology 2008 recommendations for the use of nonbiologic and biologic disease-modifying antirheumatic drugs in rheumatoid arthritis. Arthritis Care Res 2008;59:762-84.

83. Deighton C, O'Mahony R, Tosh J, Turner C, Rudolf M; Guideline Development Group. Management of rheumatoid arthritis: summary of NICE guidance. BMJ 2009;338:b702.

84. Luqmani R, Hennell S, Estrach C, Birrell F, Bosworth A, Davenport G, et al. British Society for Rheumatology and British Health Professionals in Rheumatology: Guideline for the Management of Rheumatoid Arthritis (the first two years). Rheumatology 2006;45:1167-9.

85. Fautrel B, Pham T, Gossec L, Combe B, Flipo RM, Goupille P, et al. Role and modalities of information and education in the management of patients with rheumatoid arthritis: development of recommendations for clinical practice based on published evidence and expert opinion. Joint Bone Spine 2005;72:163-70.

86. Scott DL, Steer S. NICE guidelines on anti-tumor necrosis factor therapy for RA. Nat Clin Pract Rheumatol 2009;5:16-7. 